\title{
Complete genome of Ignavibacterium album, a metabolically versatile, flagellated, facultative anaerobe from the phylum Chlorobi
}

\section{Zhenfeng Liu ${ }^{1}$, Niels-Ulrik Frigaard ${ }^{2}$, Kajetan Vogl ${ }^{1}$, Takao lino ${ }^{3}$, Moriya Ohkuma $^{3}$, Jörg Overmann ${ }^{4}$ and Donald A. Bryant ${ }^{1,5}$ *}

\footnotetext{
1 Department of Biochemistry and Molecular Biology, The Pennsylvania State University, University Park, PA, USA

2 Section for Marine Biology, Department of Biology, University of Copenhagen, Helsingør, Denmark

${ }^{3}$ Japan Collection of Microorganisms, RIKEN BioResource Center, Wako, Saitama, Japan

${ }^{4}$ Leibniz-Institut DSMZ-Deutsche Sammlung von Mikroorganismen und Zellkulturen GmbH, Braunschweig, Germany

${ }^{5}$ Department of Land Resources and Environmental Sciences, Montana State University, Bozeman, MT, USA
}

\section{Edited by:}

Ludmila Chistoserdova, University of Washington, USA

Reviewed by:

Christiane Dahl, Rheinische

Friedrich-Wilhelms-Universität Bonn,

Germany

Martin G. Klotz, University of North

Carolina at Charlotte, USA

\section{*Correspondence:}

Donald A. Bryant, Department of

Biochemistry and Molecular Biology,

The Pennsylvania State University,

108 Althouse Laboratory, University

Park, PA 16802, USA.

e-mail:dab14@psu.edu
Prior to the recent discovery of Ignavibacterium album (I. album), anaerobic photoautotrophic green sulfur bacteria (GSB) were the only members of the bacterial phylum Chlorobi that had been grown axenically. In contrast to GSB, sequence analysis of the 3.7-Mbp genome of I. album shows that this recently described member of the phylum Chlorobi is a chemoheterotroph with a versatile metabolism. I. album lacks genes for photosynthesis and sulfur oxidation but has a full set of genes for flagella and chemotaxis. The occurrence of genes for multiple electron transfer complexes suggests that $I$. album is capable of organoheterotrophy under both oxic and anoxic conditions. The occurrence of genes encoding enzymes for $\mathrm{CO}_{2}$ fixation as well as other enzymes of the reductive TCA cycle suggests that mixotrophy may be possible under certain growth conditions. However, known biosynthetic pathways for several amino acids are incomplete; this suggests that $I$. album is dependent upon on exogenous sources of these metabolites or employs novel biosynthetic pathways. Comparisons of $I$. album and other members of the phylum Chlorobi suggest that the physiology of the ancestors of this phylum might have been quite different from that of modern GSB.

Keywords: Chlorobi, Ignavibacterium album, genome sequence

\section{INTRODUCTION}

Ignavibacterium album (I. album), currently the earliest diverging, cultured member of the phylum Chlorobi (Iino et al., 2010), was recently isolated from microbial mats associated with the sulfide-rich waters of Yumata Hot Spring in Japan. Its discovery has dramatically changed the current perceptions of this phylum. Prior to the discovery of I. album, all well-characterized members of the phylum Chlorobi were physiologically similar, and the common name "green sulfur bacteria" (GSB) accurately portrayed their shared physiological characteristics (Frigaard and Bryant, 2004; Bryant and Frigaard, 2006). GSB are strictly anaerobic, nonflagellated, obligate photoautotrophs that produce chlorosomes as their light harvesting complexes. Their photosynthetic apparatus also includes the BChl $a$-binding Fenna-Matthews-Olson (FMO) protein and homodimeric, type-1 reaction centers (Bryant and Frigaard, 2006; Bryant et al., 2012). Other common metabolic features of GSB include the ability to fix $\mathrm{CO}_{2}$ through the reactions of the reverse TCA cycle (Buchanan and Arnon, 1990; Wahlund and Tabita, 1997; Tang et al., 2011); the ability to fix $\mathrm{N}_{2}$ (Wahlund and Madigan, 1993); and the ability to oxidize sulfide and other reduced sulfur compounds. Chlorobium ferrooxidans is the only known exception to the latter; it uses ferrous iron as the reductant for $\mathrm{CO}_{2}$ fixation and can perform assimilatory sulfate reduction
(Heising et al., 1999; Overmann, 2008; Frigaard and Dahl, 2009; Gregersen et al., 2011).

Ignavibacterium album cannot grow phototrophically, and it was initially described as non-pigmented and unable to synthesize (bacterio)chlorophylls, chlorosomes, FMO, or photosynthetic reaction centers. Several key photosynthesis genes could not be detected in I. album by polymerase chain reaction (PCR; Iino et al., 2010). Thus, I. album was the first, and currently remains the only, non-phototrophic member of the phylum Chlorobi that has been isolated and grown axenically in the laboratory. I. album is not a GSB and is only distantly related to other members of the Chlorobi that have been cultured; its $16 \mathrm{~S}$ rRNA sequence is only $77-83 \%$ identical to those of GSB. A phylum-wide 16S rRNA analysis showed that I. album and some other uncultured organisms represent one of five early-diverging, class-level lineages outside the class Chlorobea (Iino et al., 2010), which includes all other cultured Chlorobi that can be described as GSB (see Figure 1). On the basis of initial cultivation studies, I. album was suggested to be strictly anaerobic and non-motile; it grew fermentatively on D-glucose and yeast extract (Iino et al., 2010).

Shortly after the description of I. album and based on findings from both metagenomics and metatranscriptomics, another unconventional member of the phylum Chlorobi, "Candidatus 


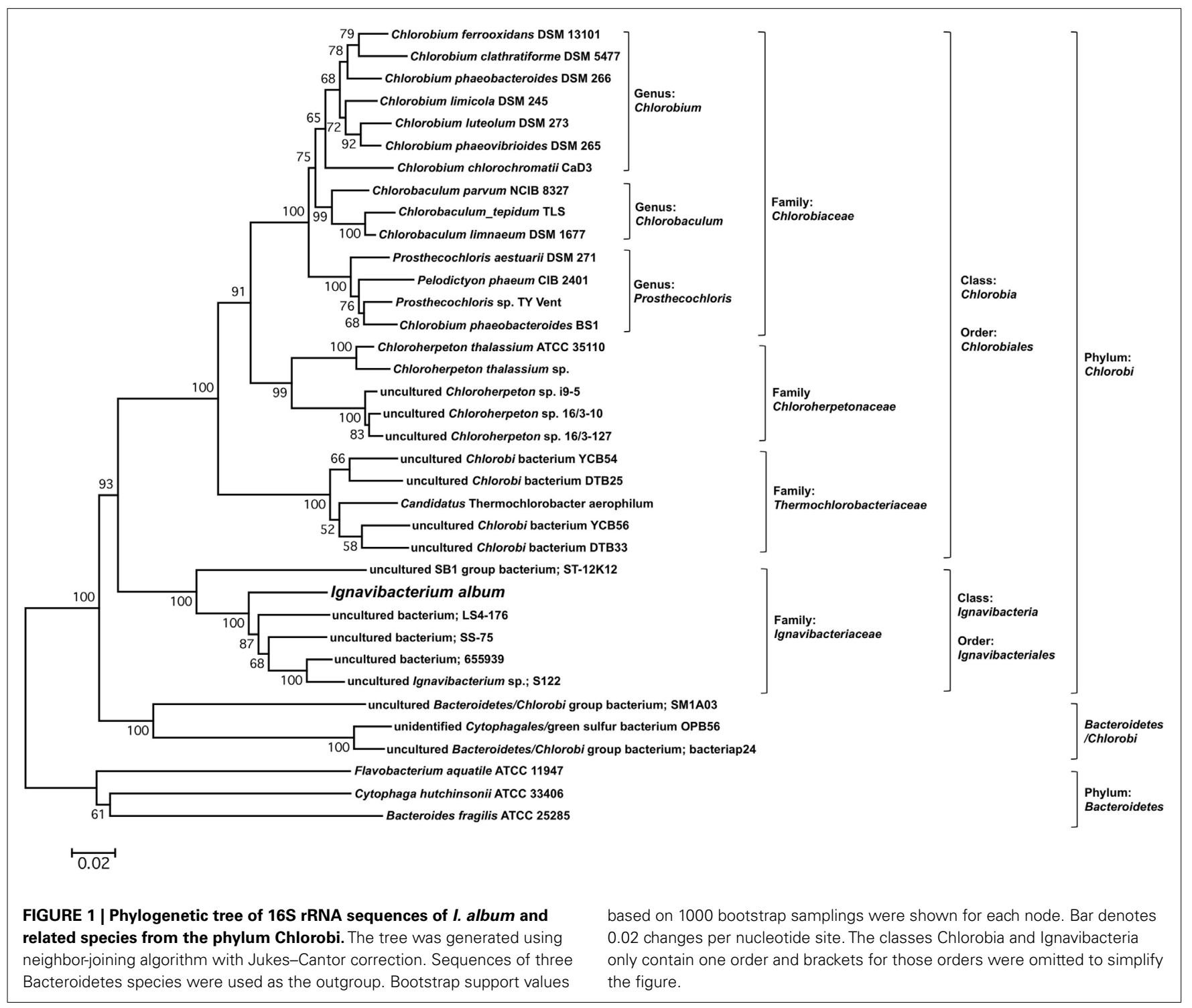

Thermochlorobacter aerophilum" (“Candidatus T. aerophilum”), was described (Liu et al., 2012). This still uncultured organism is predicted to be a photoheterotroph that cannot oxidize sulfur compounds, cannot fix nitrogen, and lacks a complete reverse TCA cycle. Unlike GSB, "Candidatus T. aerophilum" is predicted to be capable of growth under oxic conditions.

In this study we present the complete genome sequence of $I$. album and describe the physiological and metabolic capabilities of this organism that were inferred from its genome. In contrast to initial conclusions from cultivation studies with I. album, genome analyses suggest that it is a metabolically versatile organism that is capable of organoheterotrophy under both oxic and anoxic conditions. The organism also has $\mathrm{CO}_{2}$-fixing enzymes and appears to be capable of at least mixotrophic growth under certain conditions. A surprising finding was a nearly complete set of genes for the assembly of flagella and chemotaxis in the genome. Comparisons with other organisms belonging to the phylum Chlorobi are presented, and the possible implications of these findings on the evolution of photosynthesis and of the phylum Chlorobi are also discussed.

\section{METHODS AND MATERIALS} BACTERIAL STRAINS AND DNA PREPARATION

Ignavibacterium album JCM $16511^{\mathrm{T}}$ was grown at $45^{\circ} \mathrm{C}$ for 10 days in GS medium as described previously (Iino et al., 2010). Genomic DNA was extracted from $\sim 7 \mathrm{~g}$ of cells collected from $5 \mathrm{~L}$ of the culture according to the cetyltrimethylammonium bromide (CTAB) protocol for bacterial DNA isolation of the Joint Genome Institute ${ }^{1}$.

\section{GENOME SEOUENCING, ASSEMBLY, AND ANNOTATION}

Purified DNA was sequenced in a 454 pyrosequencer (GS FLX+, Roche) at the Genomics Core Facility of the Huck Institutes of

${ }^{1}$ http://my.jgi.doe.gov/general/ 
the Life Sciences at The Pennsylvania State University. A total of 554,976 paired-end reads were generated and assembled by Newbler assembler (Roche) into one large scaffold comprising 88 contigs and 34 stand-alone contigs of 500 bp or larger with an average read depth of $\sim 40 \times$. Further assembly and gap closing was managed using the phred/phrap/consed package (Ewing et al., 1998; Gordon et al., 1998). PCR products covering gaps between contigs were obtained by following suggestions from paired-end reads or by combinatorial PCR and were sequenced. Potential frame shifts were predicted using GeneTack (Antonov and Borodovsky, 2010) and either confirmed or corrected after resequencing or were modified after re-examining and editing the original assembly. The genome was annotated using a pipeline based on FGENESB software (Softberry, Inc., USA), Artemis (Sanger Institution, UK), and custom-made Perl scripts (ActivePerl; ActiveState Inc., Vancouver, $\mathrm{BC}$, USA). The rRNA genes were annotated using RNAmmer 1.2 software $^{2}$ (Lagesen et al., 2007). Naming of proteins was based primarily on the KEGG database ${ }^{3}$ and on recommendations by GenBank ${ }^{4}$. The genome sequence has been deposited in GenBank and has been assigned the accession number CP003418.

\section{PIGMENT ANALYSES}

Pigments were extracted from cell pellets of I. album by sonication in acetone:methanol $(7: 2 \mathrm{vol} / \mathrm{vol})$, and the resulting extracts were

${ }^{2}$ http://www.cbs.dtu.dk/services/RNAmmer/

${ }^{3} \mathrm{http}: / /$ www.genome.jp/kegg/

${ }^{4}$ http://www.ncbi.nlm.nih.gov/genbank/genomesubmit analyzed by high-performance liquid chromatography (HPLC) using the protocol described in Frigaard et al. (2004). The HPLC system included a binary pump (model G1312A), vacuum degasser (model G1379A), manual injector (model G1328A), and a diode-array detector (model G1315B; 1100 series; Agilent Technologies, Palo Alto, CA, USA); Agilent ChemStation software was used to control the system. The HPLC column was an analytical 5$\mu \mathrm{m}$ Discovery C18 column ( $25 \mathrm{~cm}$ by $4.6 \mathrm{~mm}$; Supelco, Bellefonte, PA, USA).

\section{RESULTS}

\section{GENOME OVERVIEW}

Ignavibacterium album has a single circular chromosome of $3,658,997$ bp with a mol\% G $+\mathrm{C}$ content of 34\% (Figure 2). The genome includes one rRNA operon, 45 tRNA genes, and 3,195 predicted protein coding sequences (open reading frames, ORFs), and 2 ORFs with frameshift mutations encoding non-functional proteins. The 3,195 ORFs were compared to the proteins of the GenBank non-redundant protein database using BLASTP, and Figure 3 shows the distribution by phylum of the best hits from this analysis. Only $\sim 15 \%$ of the most similar homologs (top BLASTP hits) in the GenBank database were proteins derived from other members of the phylum Chlorobi, with these best hits often coming from Chloroherpeton thalassium. Proteins from members of the Bacteroidetes, which share a common ancestor with members of the Chlorobi (Ludwig and Klenk, 2001; Ciccarelli et al., 2006), accounted for $\sim 26 \%$ of the most similar homologs. The remaining proteins, accounting for nearly $60 \%$ of the proteins in the genome,

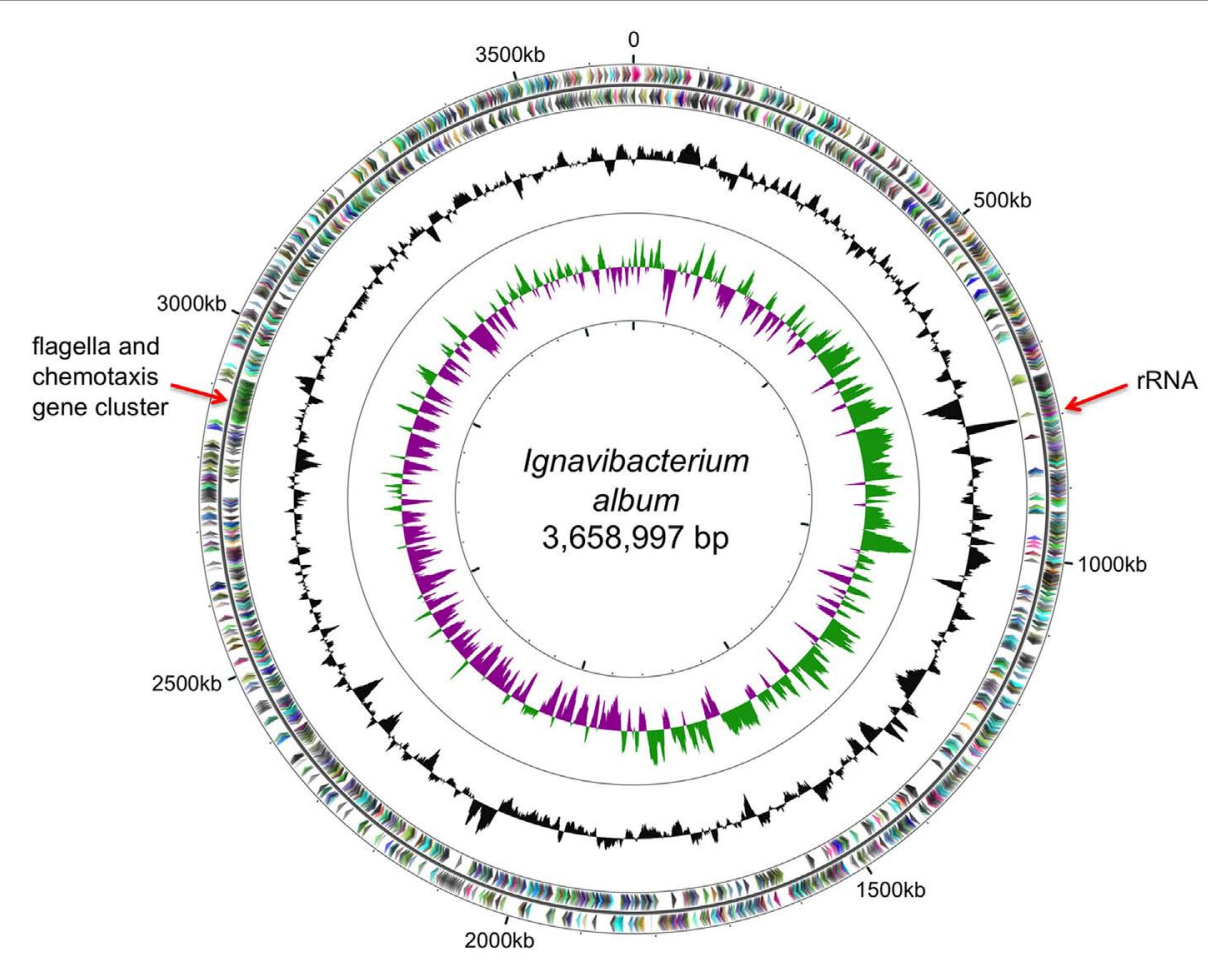

FIGURE 2 | Circular map of $\boldsymbol{I}$. album genome. Circles from outside in: genes on the forward strand; genes on the reverse strand; $\mathrm{G}+\mathrm{C} \%$ plot; and
$\mathrm{GC}$ skew plot. Baseline on the $\mathrm{G}+\mathrm{C} \%$ plot represents the average value of $34 \%$. Gene colors indicate the COG categories to which they belong. 
were either most similar to proteins of very distantly related organisms, including members of the Proteobacteria (16.2\%), Firmicutes $(9.0 \%)$, or "Others" $(21.4 \%)$, or had no hits in the database $(12.4 \%)$. The data in Figure 3 demonstrate the relative uniqueness of I. album within the broader context of current knowledge of the comparative genomics of other members of the Chlorobi. This distribution of most similar homologs will probably change significantly when the genomes of additional, early-diverging members of the Chlorobi are characterized, especially those belonging to organisms other than GSB. It should be noted that the absence of well-characterized close relatives of I. album inevitably increases the uncertainty of inferences about its metabolism and physiology.

Consistent with the distant relationship between I. album and GSB, 273 of the 813 orthologous core proteins shared by 12 GSB (Bryant et al., 2012) were absent in the I. album genome. Among the missing genes were all genes related to photosynthesis, such as those encoding subunits of the photosynthetic reaction center ( $p s c A, p s c B, p s c C, p s c D$ ), fmoA, (bacterio) chlorophyll biosynthesis, and genes encoding chlorosome envelope proteins. These observations confirmed results from cultivation studies, which showed that I. album is non-phototrophic, as well as negative results from attempts to amplify photosynthesis-related genes by PCR (Iino et al., 2010).

\section{CENTRAL CARBOHYDRATE METABOLISM}

The I. album genome encodes a complete set of genes for glycolysis, the TCA cycle, and gluconeogenesis, and these observations are consistent with observation that it can grow with glucose or other oligosaccharides as sole carbon source (Iino et al., 2010). The genome also includes genes for glycogen synthase and glycogen phosphorylase, which suggests that glycogen is its major storage compound. Genes for polyhydroxyalkanoate synthesis and degradation were not detected. I. album probably produces acetate and L-lactate as the main products when growing fermentatively. Common pathways for fermentative production of propionate (via methylmalonyl-CoA carboxyltransferase), ethanol (via alcohol dehydrogenase), and formate (via pyruvate formate lyase) are apparently incomplete or missing altogether.
Ignavibacterium album possesses genes encoding two $\mathrm{CO}_{2}$ fixing enzymes pyruvate:ferredoxin oxidoreductase (PFOR; IALB_2949) and 2-oxoglutarate:ferredoxin oxidoreductase (KFOR; IALB_1501, IALB_1502), which are essential for autotrophic $\mathrm{CO}_{2}$ fixation in GSB (Feng et al., 2010). Because the glyoxylate cycle is not present, PFOR is probably essential for the assimilation of acetate by carboxylation of acetyl-CoA to pyruvate. Unlike its GSB relatives, the I. album genome does not encode ATP-dependent citrate lyase, which is a key enzyme required for autotrophic $\mathrm{CO}_{2}$ fixation by the reverse TCA cycle in GSB (Wahlund and Tabita, 1997). The genes for alternative enzymes found in other organisms with reverse TCA cycle activity, namely citryl-CoA synthetase and citryl-CoA lyase (Aoshima et al., 2004a,b), and the postulated type II ATP-dependent citrate lyase (Hügler and Sievert, 2011), were also absent. However, the I. album genome does include genes (IALB_1146, IALB_1147) that encode an ATPindependent citrate lyase (Bott and Dimroth, 1994). IALB_1146 encodes the $\alpha$ subunit, CitF, while IALB_1147 encodes a fusion of the $\beta$ and $\gamma$ subunits, CitE and CitD. This enzyme catalyzes the cleavage of citrate to acetate and oxaloacetate, and it is involved in citrate fermentation in some organisms (Meyer et al., 2001). It is possible that this enzyme performs the same function in I. album. In support of this possibility, a putative citrate transporter gene (IALB_1014) occurs in the genome. Although this role has not yet been proposed for this enzyme, an interesting possibility that must be considered is that the ATP-independent citrate lyase could also function in the reverse TCA cycle in $I$. album. If so, this organism would then possess a complete reverse TCA cycle. The operation of the reverse TCA cycle for $\mathrm{CO}_{2}$ assimilation would also depend upon the availability of electron sources to produce reduced ferredoxin. The genome of I. album includes genes necessary to take advantage of some potential electron sources and for the production of reduced ferredoxin from them (see below). In conclusion, the gene content of the I. album genome shows that the organism can probably grow mixotrophically. Additionally, it may have a complete but unconventional reverse TCA cycle (Figure 4), but this hypothesis will have to be tested experimentally.

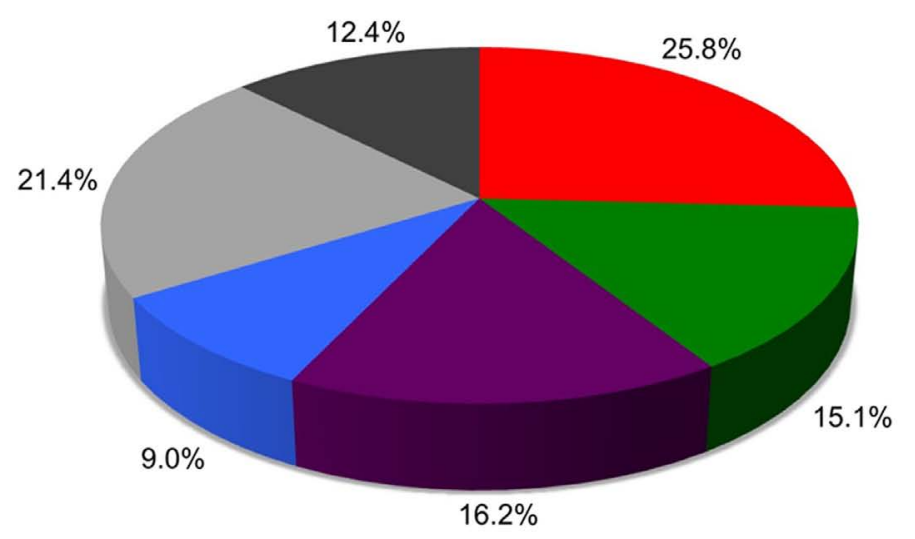

Bacteroidetes
Chlorobi
Proteobacteria
Firmicutes
Others
No hits

FIGURE 3 | Phylogenetic distribution of BLASTP best hits of $I$. album proteins compared to proteins in the NCBI nr database. An e-value cut-off of 0.001 was used. 


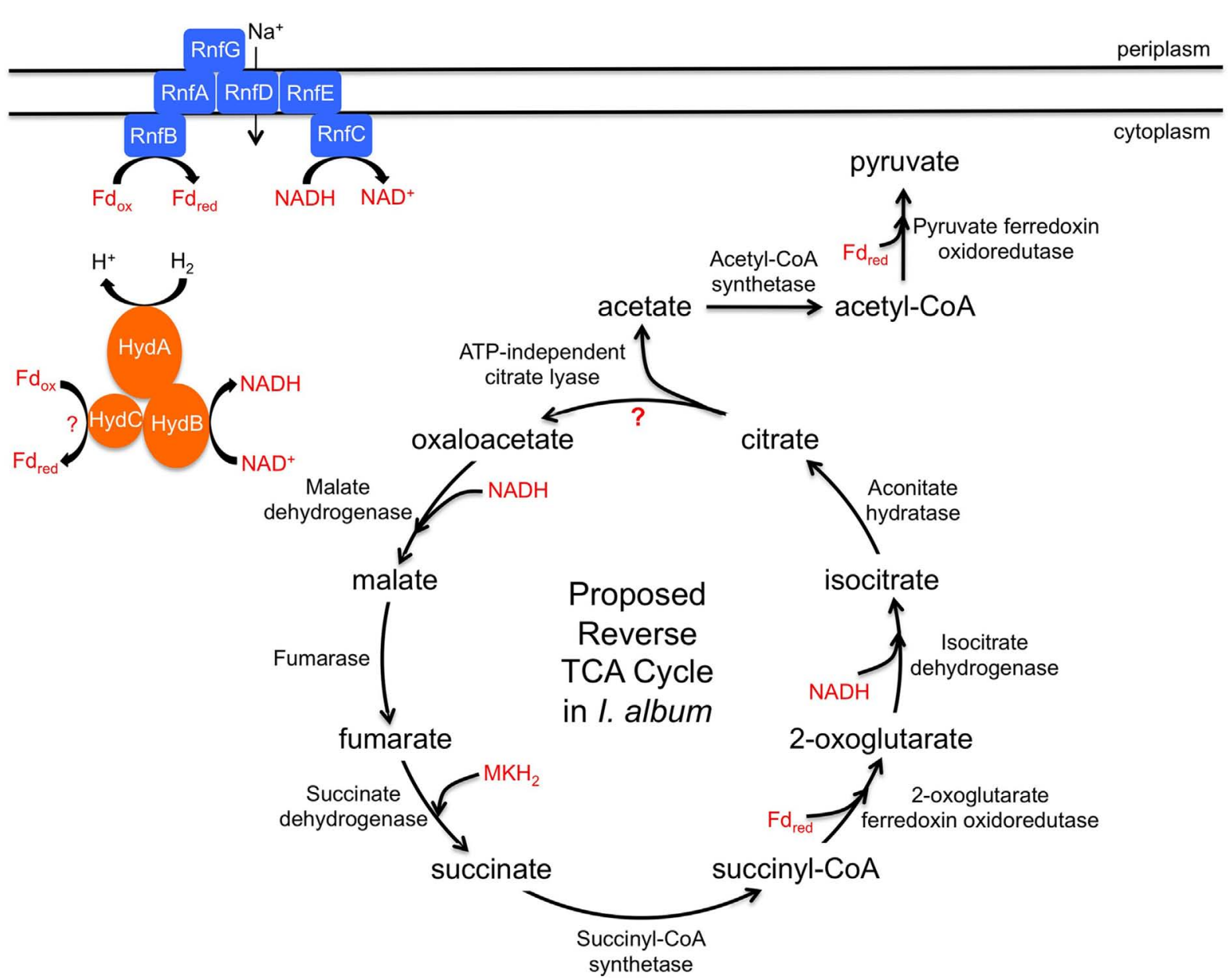

FIGURE 4 | Proposed mixotrophy and a potential unconventional reverse TCA cycle in $\boldsymbol{I}$. album. Fd, ferredoxin; red, reduced; ox, oxidized; Hyd, hydrogenase; $\mathrm{MKH}_{2}$, menaquinol; Rnf, $\mathrm{Na}^{+}$-translocating ferredoxin: $\mathrm{NAD}^{+}$oxidoreductase.

\section{ELECTRON CARRIERS}

Ignavibacterium album has a complete set of men genes for the synthesis of menaquinone and HPLC analyses show that I. album produces menaquinone-7 like GSB (Iino et al., 2010; Figure 5A). Genes for enzymes of ubiquinone biosynthesis were not detected. The I. album genome encodes at least nine ferredoxins, including both $2 \mathrm{Fe}-2 \mathrm{~S}$ and $4 \mathrm{Fe}-4 \mathrm{~S}$ types, which have different sensitivities to $\mathrm{O}_{2}$ (Jagannathan and Golbeck, 2008) and thus might function under different $\mathrm{O}_{2}$ conditions. Interestingly, genes encoding rubredoxins were not detected.

\section{ELECTRON TRANSFER COMPLEXES}

The I. album genome encodes a variety of electron transfer complexes, including the RNF $\left(\mathrm{Na}^{+}\right.$-translocating ferredoxin: $\mathrm{NAD}^{+}$ oxidoreductase) complex (Biegel et al., 2011), two type-1 NADH dehydrogenase complexes, and alternative complex III (ACIII). Multiple terminal electron transfer complexes, including those for growth under oxic and anoxic conditions, were also present in the genome (see Figure 6 and below). The presence of such a wide spectrum of electron transfer complexes likely reflects an ability of I. album to utilize the different electron carriers used by various redox enzymes as well as the various terminal electron acceptors that might be available in situ.

An eight-gene cluster (IALB_0246 to 0253) includes the rnfCDGEAB genes, which encode the RNF complex, as well as two other genes whose functions are unclear. The RNF complex creates $\mathrm{a} \mathrm{Na}^{+}$gradient across the cytoplasmic membrane that can be used to produce ATP when reduced ferredoxins are oxidized by $\mathrm{NAD}^{+}$. This complex could also operate in reverse to oxidize NADH and produce reduced ferredoxins, which are the required reductants for important anabolic reactions, such as the ones catalyzed by KFOR and PFOR mentioned above. Unlike its GSB relatives, $I$. album does not have a photosynthetic apparatus to produce the reduced ferredoxins required for carbon fixation by the reverse TCA cycle. Therefore, the RNF complex, which might provide a major route for the production of such reductants, would probably play an important role in the energy metabolism of I. album. Although all GSB produce reduced ferredoxins using their type-1 homodimeric reaction centers, several GSB genomes also possess homologs of the rnfgenes found in I. album. Other than KFOR and PFOR, the I. album genome includes genes for two other 2-oxoacid:ferredoxin oxidoreductases: 2-oxo-isovalerate oxidoreductase 

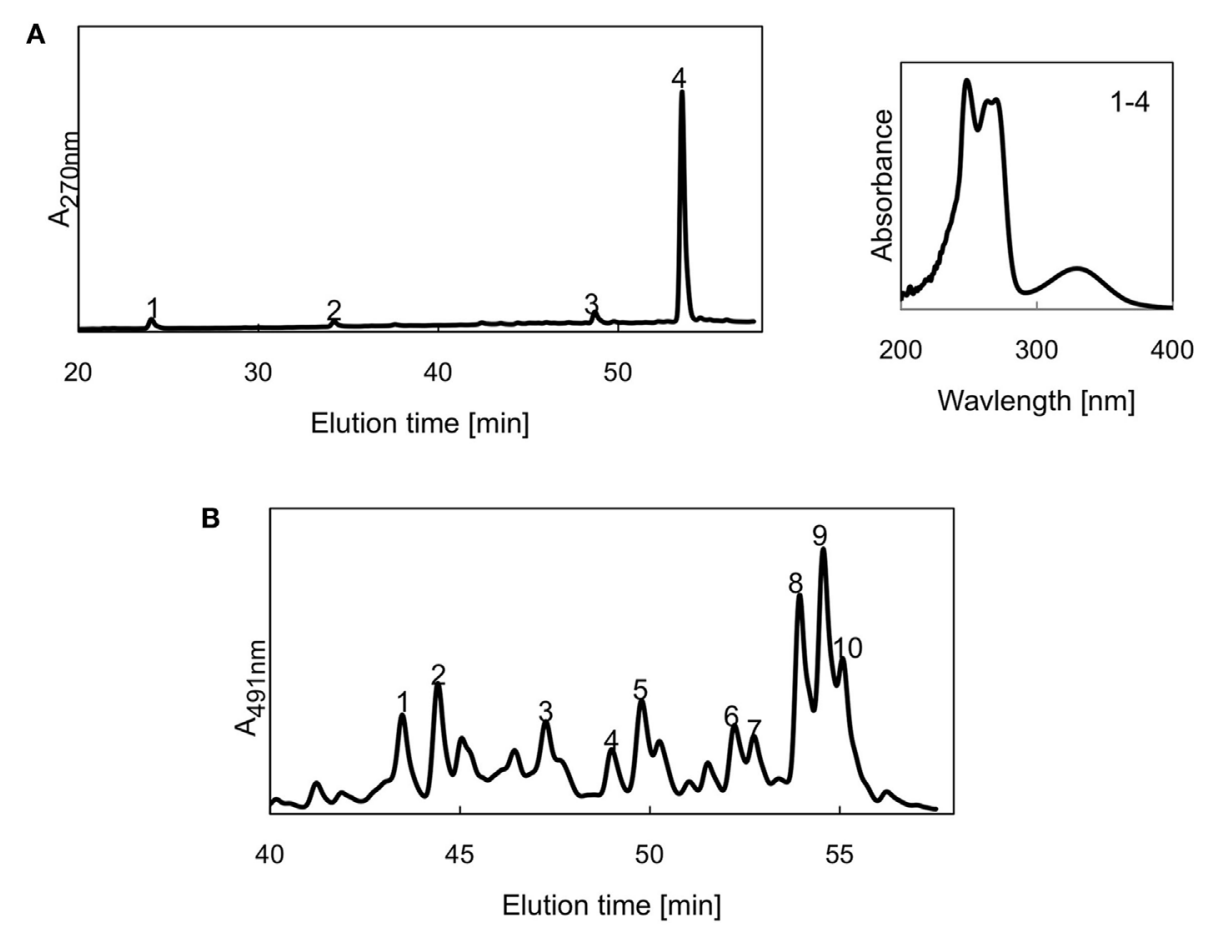

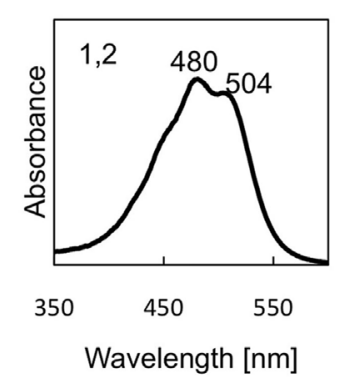

FIGURE 5 | High-performance liquid chromatography elution profile of pigments produced in $\boldsymbol{I}$. album. The in-line absorption spectra of the peaks are shown in the numbered boxes. (A) Elution profile monitoring absorbance

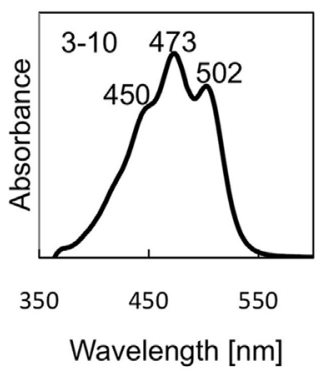

at $270 \mathrm{~nm}$. Peaks 1-4, menaquinones. (B) Elution profile monitoring absorbance at $491 \mathrm{~nm}$. Peaks 1, 2, deoxyflexixanthin derivatives; peaks 3-10 1 '-hydroxytorulene derivatives.
(VOR) and indole-pyruvate oxidoreductase (IOR). VOR and IOR have been shown to function in amino acid fermentation and/or synthesis (Tersteegen et al., 1997).

The I. album genome includes two sets of genes encoding type$1 \mathrm{NADH}$ dehydrogenase (NDH-1). One set forms an apparent operon (IALB_1622 to 1632) that, compared to Escherichia coli $\mathrm{NDH}-1$, is missing three genes, nuoEFG (Figure 7A). This gene cluster is also conserved in all sequenced GSB genomes. Only C. thalassium, which has a full set of 14 nuo genes, and "Candidatus T. aerophilum," which has 12 nuo genes, have additional $\mathrm{NDH}-1$ genes. Without the subunits for the diaphorase activity, this complex should not function as an NADH:quinone oxidoreductase. It has been suggested that such NDH complexes may couple with hydrogenase or ferredoxin:quinone oxidoreductase, or receive electrons directly from reduced ferredoxin(s), to complete their functionality in electron transport (Eisen et al., 2002; Battchikova et al., 2011). The other genes for NDH-1 are divided into three gene clusters, which include homologs for all 14 subunits of the NDH-1 of E. coli (Figure 7A). Although the genes fall into different gene neighborhood groupings, $C$. thalassium is the only GSB that has a complete set as well as additional NDH-1 genes. The products of these genes are expected to form a complex functioning as an NADH:quinone oxidoreductase. Phylogenetic analyses of these two sets of genes indicate that they are relatively distantly related, and that they did not arise from recent gene duplication. The subunits of both NDH-1 complexes are similar to proteins that occur in various members of the Bacteroidetes, and thus these genes may have been present in the ancestors of extant members of the Chlorobi (Figure 8A). It is interesting that the three earliest diverging members among Chlorobi whose genomes have been sequenced, I. album, "Candidatus T. aerophilum," and C. thalassium, each have two sets of NDH-1 genes. It seems likely that ancestral members of the Chlorobi had both copies and that the genes for one of them (the 14-gene set) was lost in the lineage leading to the ancestor of extant GSB strains. 


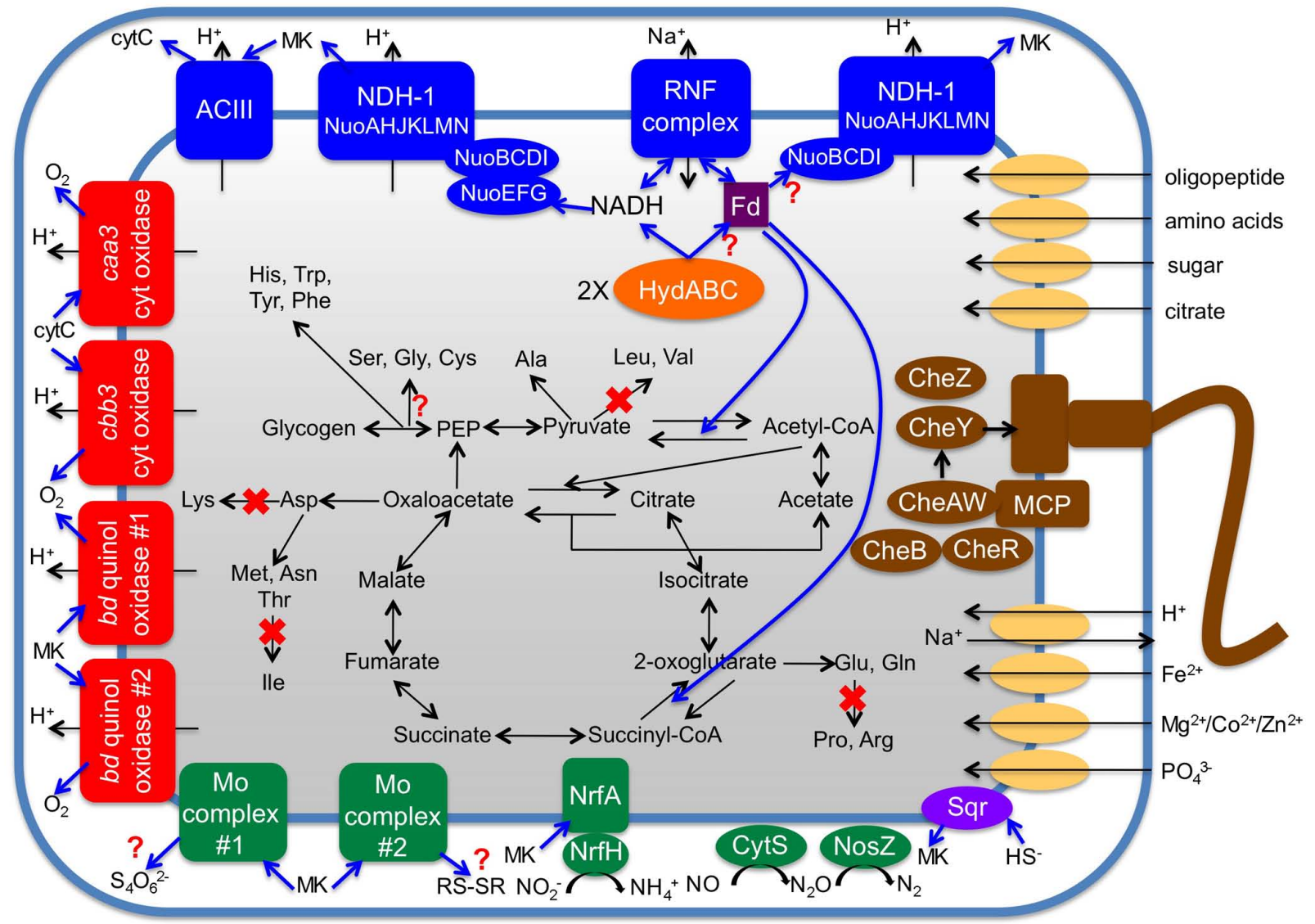

FIGURE 6 | Cellular overview of $\boldsymbol{l}$. album metabolism deduced from its genome sequence. Only selected pathways and enzymes discussed in the text are shown. Blue arrows indicate pathways of electron flow. NDH-1, type-1 NADH dehydrogenase; Fd, ferredoxin; MK, menaquinone; cyt, cytochrome; Mo complex, complexes containing a molybdopterin-guanine dinucleotide cofactor; ACIII, alternative complex III.

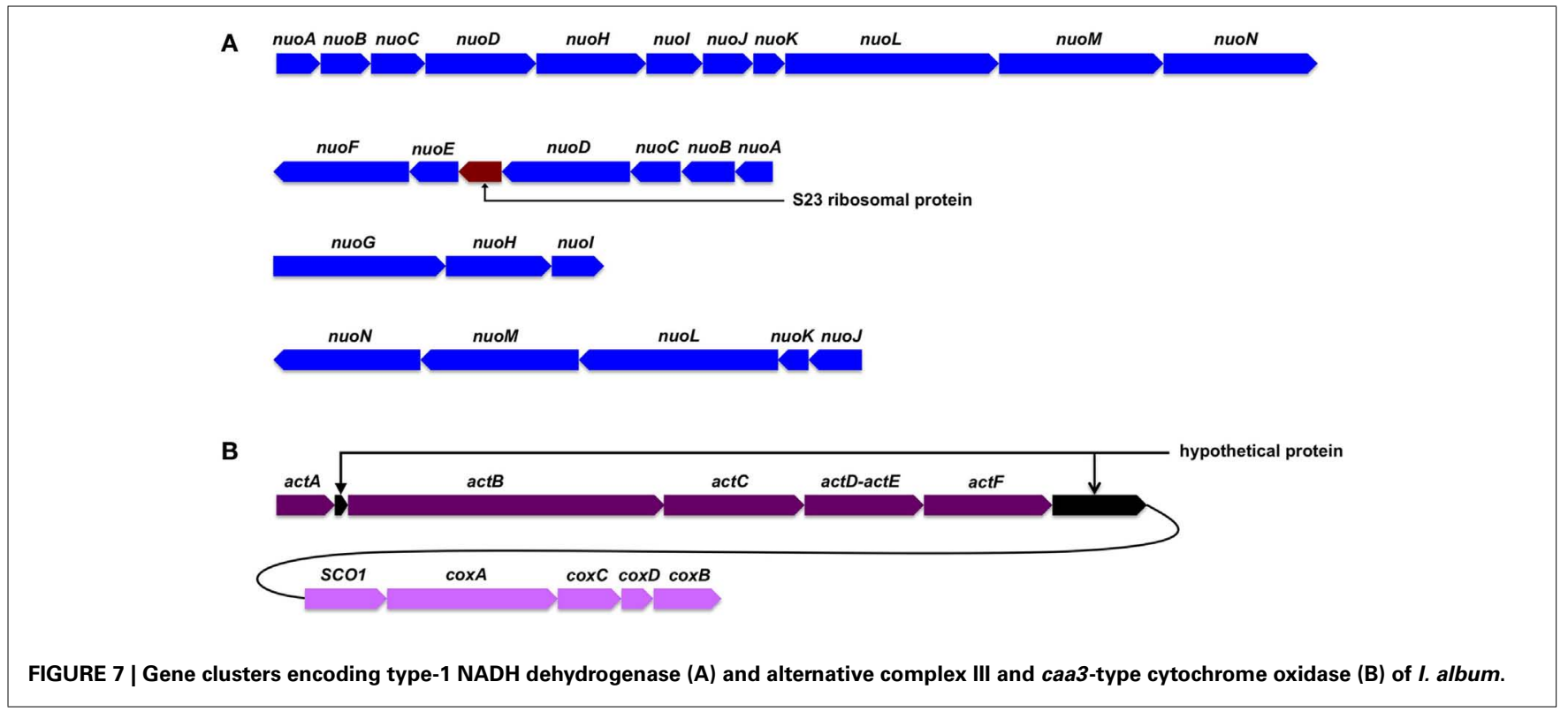



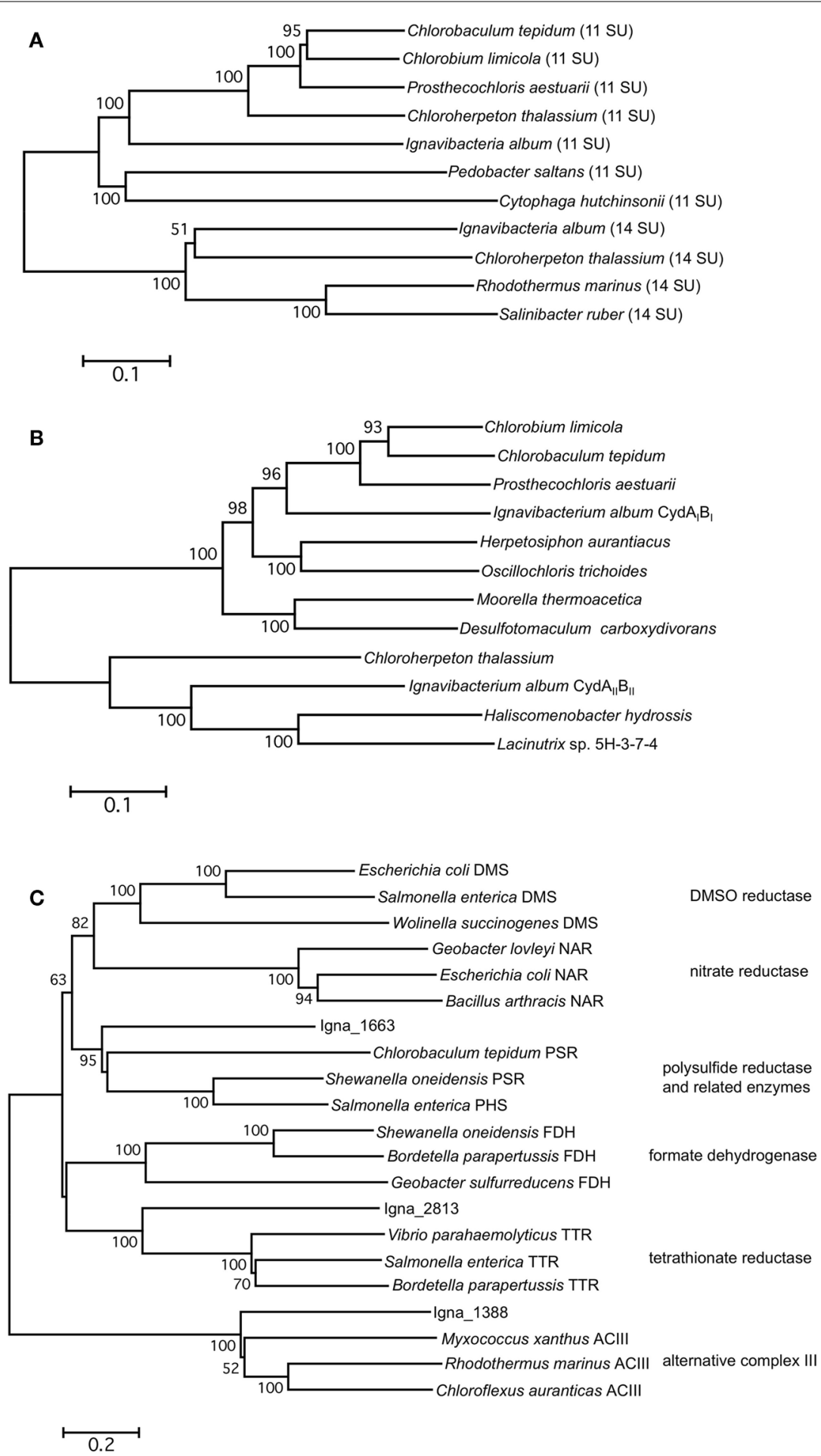

FIGURE 8 | Phylogenetic trees type-1 NADH dehydrogenase proteins (A), cytochrome bd-quinol oxidases (B), and molybdopterin-guanine dinucleotide cofactor-containing complexes (C) from I. album and other organisms. Concatenated NuoABCDHIJKLMN protein sequences were used for (A); concatenated CydAB protein sequences were used for (B); molybdopterin-guanine dinucleotide-containing subunit sequences were used for (C). Trees were created using the neighbor-joining algorithm from 100 bootstrap samplings. Bootstrap support values over $50 \%$ are shown. Scale bars denote $X$ changes per amino acid where $X$ is the number above bars. SU, subunits. (C) was adapted from Yanyushin et al. (2005) and was recreated by including I. album proteins. 
Unlike its GSB relatives, all of which have cytochrome $b$-Rieske type complexes, i.e., quinol:electron acceptor oxidoreductases, $I$. album has ACIII, which is a phylogenetically unrelated electron transfer complex that performs the same function (Pereira et al., 2007; Gao et al., 2009). The gene cluster (IALB_1386, 1388, 1389, 1390, and 1391) encoding ACIII is very similar to the gene clusters that have been characterized in Rhodothermus marinus and Chloroflexus aurantiacus. An exception is that IALB_1390 codes for a fusion protein of ActD and ActE (Figure 7B), which are normally produced as separate gene products in other organisms. The genes for ACIII are often clustered with those for cytochrome $c$ oxidases (Refojo et al., 2010a), and functional coupling between these two complexes has been demonstrated (Refojo et al., 2010b). The clustering of these genes is also observed in I. album genome (Figure 7B) and suggests that they are probably involved in respiration under oxic conditions. Together with some additional evidence (see below), these observations strongly suggest that $I$. album is not a strict anaerobe as previously reported on the basis of cultivation studies (Iino et al., 2010). ACIII is much more widely distributed than the cytochrome $b$-Rieske complex among members of the Bacteroidetes (Refojo et al., 2010a). "Candidatus T. aerophilum" has both ACIII as well as two different cytochrome $b$ Rieske complexes (Liu et al., 2012). These data suggest that ACIII was probably present in the ancestor of the Chlorobi and that cytochrome $b$-Rieske type complexes were obtained and ACIII was then lost during evolution of extant GSB.

Ignavibacterium album has four different oxygen-dependent terminal oxidases, including $\mathrm{caa}_{3}$-type (IALB_1394 to 1397) and $c b b_{3}$-type (IALB_0721 and 0723) heme-copper cytochrome $c$ oxidases and two different cytochrome $b d$-quinol oxidases (Figure 6). The quinol oxidase complexes are only distantly related; one (IALB_0420 and 0421) is similar to homologs found in most GSB, and the other (IALB_1098 and 1099) is similar to homologs that occur in C. thalassium and members of the Bacteroidetes (Figure 8B). The potential functional difference between these two complexes is unclear from these sequence analyses alone. However, the data seem to imply that ancestors of Chlorobi might have had two quinol oxidases like I. album, and C. thalassium and other GSB subsequently inherited different ones. All three types of terminal oxidases could participate in aerobic respiration and/or protection against reactive oxygen species (Garica-Horsman et al., 1994; Li et al., 2009; Hassani et al., 2010). The $c b b_{3}$ cytochrome oxidase and cytochrome $b d$-quinol oxidase typically have much higher affinity for $\mathrm{O}_{2}$ than the $\mathrm{caa}_{3}$ cytochrome oxidase (van der Oost et al., 1994; D’Mello et al., 1996; Preisig et al., 1996), and because of this, they are frequently involved in protecting anaerobes from reactive oxygen species. The distribution of these complexes in members of the Chlorobi is consistent with this general trend. Strictly anaerobic GSB only have one or both of the high-affinity terminal oxidases (Li et al., 2009), while the aerobe, "Candidatus T. aerophilum," only has the cytochrome $\mathrm{caa}_{3}$ oxidase (Liu et al., 2012). The presence of all three types of complexes in I. album strongly suggests that $\mathrm{I}$. album experiences varying $\mathrm{O}_{2}$ concentrations in situ. The presence of these different terminal oxidases in I. album would confer not only the ability to respire under oxic conditions but also the ability to protect oxygen-sensitive enzymes such as hydrogenase under microoxic conditions.

\section{OXIC METABOLISM}

Additional evidence in the genome supports the deduction that I. album should grow under oxic conditions. I. album has genes encoding both catalase (IALB_0054) and superoxide dismutase (IALB_1637), which protect organisms exposed to $\mathrm{O}_{2}$ from reactive oxygen species. I. album also has an oxygen-dependent protoporphyrinogen oxidase (HemY, IALB_0230; Dailey and Dailey, 1996) for heme biosynthesis, and it also has several putative dioxygenases that are not found in any GSB genome. In its central metabolism, I. album has genes for the catabolic enzymes pyruvate dehydrogenase and 2-oxoglutarate dehydrogenase, which are typically found in, but are not exclusively limited to, aerobes. However, the presence of these genes implies that I. album frequently is in contact with oxygen and even utilizes oxygen as a substrate in some of its key metabolic pathways. Although I. album was initially grown under strictly anoxic conditions (Iino et al., 2010), more recent cultivation studies have confirmed that $I$. album can grow in the presence of oxygen concentrations ranging from 1 to $20 \%$ (v/v; data not shown). In summary, I. album is at least a facultative anaerobe, but it may be capable of growth under microoxic or even oxic conditions, provided that other nutrients required for growth are provided.

\section{ANAEROBIC RESPIRATION}

In addition to ACIII, I. album possesses genes encoding two additional oxidoreductases predicted to contain molybdopteringuanine dinucleotide cofactors. A phylogenetic analysis of the other two complexes and other related enzymes was conducted to predict their substrate specificity. One of them (IALB_1661 to 1663 ) is related to polysulfide and thiosulfate reductases (Hinsley and Berks, 2002), and the other (IALB_2813 to 2815) is most similar to tetrathionate reductases (Hensel et al., 1999; Figure 8C). Such predictions are obviously provisional and require further experimental testing. Whatever the actual substrate specificity, these membrane-bound complexes could potentially function in respiration under anoxic conditions.

Ignavibacterium album also has genes encoding respiratory nitrite reductase, nitric oxide reductase, and nitrous oxide reductase (Figure 6). The nitrite reductase is a membrane-bound complex consisting of two proteins, NfrA (IALB_0860) and NfrH (IALB_0861), which catalyze the ammonification of nitrite using menaquinol as the electron donor (Simon, 2002). I. album does not have any NO reductases belonging to the heme-copper oxidase family, such as cNor, qNor, sNor, or gNor, but its genome encodes a tetraheme cytochrome $c$-type NO reductase CytS (Upadhyay et al., 2006; IALB_3191). It is also possible that one or both of the two heme-copper cytochrome $c$ oxidases might function as an NO reductase under anoxic conditions (Giuffrè et al., 1999; Forte et al., 2001). Nitrous oxide reductase is a soluble, periplasmic enzyme that catalyzes the reduction of $\mathrm{N}_{2} \mathrm{O}$ to $\mathrm{N}_{2}$ using cytochrome $c$ as the electron donor (Zumft and Körner, 2007). Genes encoding the enzyme (NosZ; IALB_0848) and its accessory proteins (NosLDFY; IALB_0851 to 0854) are co-localized in an operon and are nearby the $n f r$ genes. I. album does not appear to have the other denitrification/ammonification enzymes (i.e., nitrate reductase, NO-producing nitrite reductase). This observation suggests 
that there might be other denitrifying organisms in situ that live together with I. album and produce $\mathrm{NO}_{2}^{-}$and $\mathrm{NO}$.

\section{INORGANIC ELECTRON DONORS}

Ignavibacterium album has two three gene clusters (IALB_0255 to 0257 and IALB_0529 to 0531) that encode two different [FeFe]hydrogenases. The hydEFG genes (IALB_0525, 0528, and 0526), which encode the assembly proteins for such hydrogenases (Vignais and Billoud, 2007; McGlynn et al., 2008; Mulder et al., 2011) occur immediately upstream from one of the hydrogenase operons. The predicted heterotrimeric hydrogenases are similar in sequence and subunit composition to the bifurcating hydrogenase, which is both NADH and ferredoxin-dependent, and which has been characterized in Thermotoga maritima ( T. maritima; Verhagen et al., 1999; Schut and Adams, 2009). However, the HydA subunits of both hydrogenases lack the extra C-terminal [2Fe-2S] domain that occurs in T. maritima HydA. Instead, these HydA subunits are more similar to HydA subunit of the NADH-dependent, tetrameric hydrogenase of Thermoanaerobacter tengcongensis ( $T$. tengcongensis; Soboh et al., 2004). Additionally, the HydB subunits of the two predicted hydrogenases are different; IALB_0530 has an N-terminal [2Fe-2S] and two C-terminal [4Fe-4S] clusters other than the NuoF-like $\mathrm{FMN}$ and $\operatorname{NAD}(\mathrm{P})(\mathrm{H})$ binding domain like HydB of T. maritima and T. tengcongensis hydrogenases, but IALB_0256 does not have these extra Fe-S clusters (Figure 9). The exact enzymatic activities of these two hydrogenases are unclear, but it seems safe to assume they use $\operatorname{NAD}(\mathrm{P})(\mathrm{H})$ as one, if not the only electron donor/acceptor. Fe-only hydrogenases are often associated with $\mathrm{H}_{2}$ evolution (Vignais and Billoud, 2007), and this was also the case in vivo when the related hydrogenases of T. maritima and $T$. tengcongensis were characterized. Thus, it appears likely that $I$. album could use these enzymes to establish redox balance during fermentation (i.e., removal of excess electrons by proton reduction). The production of $\mathrm{H}_{2}\left(\mathrm{E}_{0}^{\prime}=-420 \mathrm{mV}\right)$ using $\mathrm{NADH}$ electrons $\left(\mathrm{E}_{0}^{\prime}=-320 \mathrm{mV}\right)$ is energetically unfavorable, and the $T$. tengcongensis hydrogenase catalyzes $\mathrm{H}_{2}$ oxidation at greater rates than $\mathrm{H}_{2}$ production in vitro (Soboh et al., 2004). However, under a high partial pressure of $\mathrm{H}_{2}$ and/or low $\mathrm{NADH} / \mathrm{NAD}^{+}$ratio, one or both of these enzymes could oxidize $\mathrm{H}_{2}$ oxidation and allow $I$. album to use $\mathrm{H}_{2}$ as an electron donor. Detailed sequence analyses identified a cysteine to serine substitution in the L1 H cluster binding motif of IALB_0257, similar to T. tengcongensis HydA (E. Boyd, personal communication). This substitution is hypothesized to bias the redox potential of this $\mathrm{Fe}-\mathrm{S}$ cluster toward $\mathrm{H}_{2}$ oxidation (Posewitz et al., 2008). The difference in the HydB subunits of the two hydrogenases could also indicate possible differences in substrate specificity, i.e., whether ferredoxin is involved, and the favored directionality of the reaction. These differences must be tested experimentally. However, if some of the postulated functions can be experimentally verified, the predictions from the genome suggest that I. album could exhibit considerable versatility in its ability to utilize $\mathrm{H}_{2}$ and protons as electron donor and acceptor, respectively.

The I. album genome encodes two sulfide-quinone oxidoreductases. Phylogenetic analyses indicated that IALB_1101 belongs to the SqrD family and IALB_0172 belongs to the SqrE family (Gregersen et al., 2011). However, the presence of these two genes does not necessarily mean that I. album can use sulfide as an electron donor, because $C$. ferrooxidans, which does not grow on sulfide (Heising et al., 1999), also has two sulfide-quinone oxidoreductases, SqrD and SqrF (Gregersen et al., 2011). The two enzymes could simply be used for sulfide detoxification by formation of sulfur/polysulfide. I. album does not have any other examples of the dozens of other genes involved in sulfide/thiosulfate/sulfur/sulfite oxidation that are characteristically and almost universally found in GSB genomes. Although I. album was isolated in a medium containing a high concentration of sulfide (lino et al., 2010), its sulfur oxidation activity has not yet been studied.

Although I. album has two genes (IALB_2573 and 2574) that are very similar to the large and small subunits of an aerobic CO

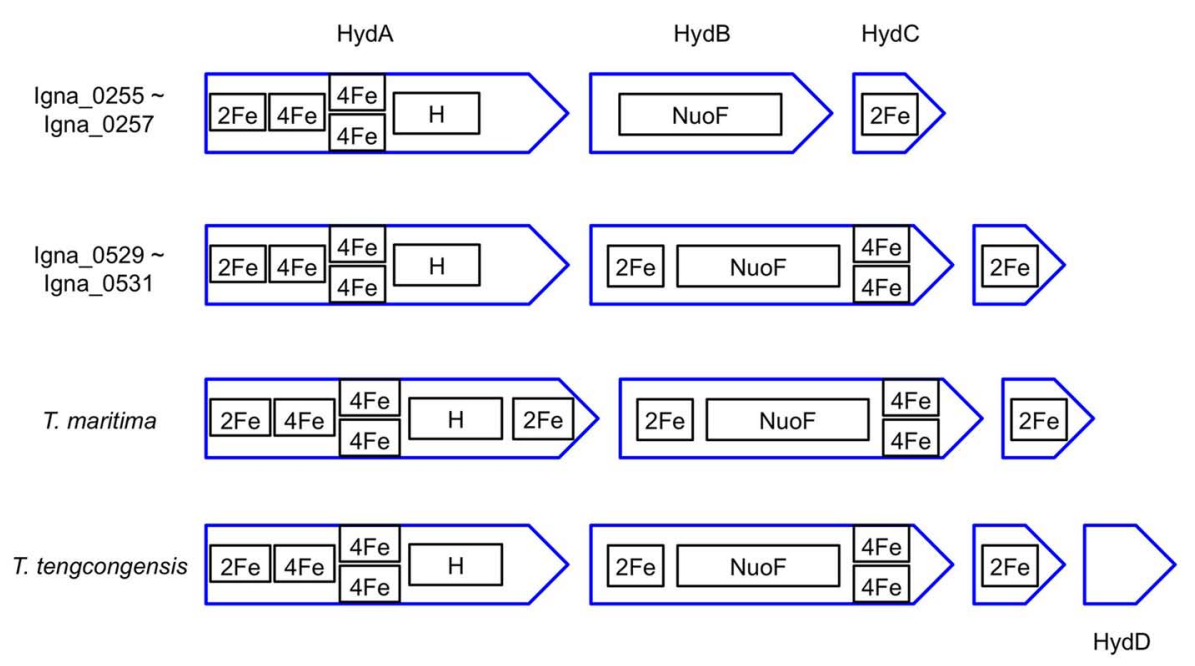

FIGURE 9 | Schematic representation of the predicted Fe/S cluster contents of two hydrogenases from $I$. album compared to two related and experimentally characterized hydrogenases from Thermotoga maritima and Thermoanaerobacter tengcongensis. $\mathrm{H}, \mathrm{H}$ cluster; $2 \mathrm{Fe}$, [2Fe-2S] cluster; 4Fe, [4Fe-4S] cluster; NuoF, FMN and NAD(P)(H) binding domain. 
dehydrogenase, it lacks the conserved medium-sized subunit (King and Weber, 2007). Therefore, the products of these two genes may not encode a CO dehydrogenase but may be more closely similar to other members of the molybdopterin hydroxylase family, such as xanthine dehydrogenase and aldehyde oxidoreductase (Dobbek et al., 1999). The I. album genome does not encode known enzymes that use other inorganic electron donors such as $\mathrm{Fe}^{2+}, \mathrm{NH}_{4}^{+}, \mathrm{NO}_{2}^{-}$, or arsenite.

\section{CAROTENOID BIOSYNTHESIS}

Because I. album was originally reported to be non-pigmented [albus (Latin) white], one unexpected finding was that the genome included a gene cluster encoding enzymes of carotenogenesis. Homologs of crtB, crtI, crtD, crtY, cruF, cruC, cruD, and crtW (Maresca et al., 2008) were found in the genome. HPLC analyses and absorption spectra of carotenoids extracted from I. album suggested that two pigments are produced, 1-OH-torulene and deoxyflexixanthin (Figure 5B), which is derived from $\gamma$-carotene. These pigments are consistent with predictions based upon the genes identified (Maresca et al., 2008; Garcia Costas et al., 2012b; Tsukatani et al., 2012). The complexity of the elution profile for the carotenoids probably arises from the attachment of different glycosyl groups to the $\psi$-end of these molecules and to differences in the attached fatty acyl groups in the case of carotenoid glycosyl-fatty acyl esters. Similar complexity has been observed for the carotenoids produced by other members of hot spring microbial mats, including Thermomicrobium roseum and "Candidatus C. thermophilum” (Maresca et al., 2008; Wu et al., 2009; Garcia Costas et al., 2012b; Tsukatani et al., 2012).

\section{AMINO ACID BIOSYNTHESIS}

The I. album genome is missing key genes involved in the biosynthetic pathways for several amino acids (Figure 6). For example, only the aminotransferases for the corresponding 2-oxo-acid precursors of valine, leucine, and isoleucine biosynthesis were found in the I. album genome. Interestingly, these missing genes are similarly absent in "Candidatus C. thermophilum" (Garcia Costas et al., 2012a) and "Candidatus T. aerophilum" (Liu et al., 2012). Similar to suggestions made for these two organisms, I. album must either have a novel biosynthetic pathway for branched chain amino acids, or it obtains them or some biosynthetic precursors, such as the corresponding 2-oxo-acids, from its environment. Unlike the other two organisms mentioned above, I. album has a putative 2oxo-isovalerate:ferredoxin oxidoreductase, which could produce 2-oxo-acids by carboxylation of simpler substrates. It seems highly unlikely that three distantly related organisms, all found in hot spring microbial mats, would have independently gained novel enzymes to synthesize these amino acids. It seems more parsimonious to suggest that these organisms obtain these amino acids, or some biosynthetic precursor(s), from their environment through other members of the microbial mat communities. Unfortunately, information is currently very limited concerning the other organisms that are present in the microbial mats from which I. album was isolated.

Other unidentified genes for enzymes of amino acid biosynthesis included thrA, lys $C$, asd, and dapABD of lysine biosynthesis; $\arg G H$ for arginine biosynthesis; and proC of proline biosynthesis, all of which are highly conserved in all GSB. No known complete, alternative pathways for the synthesis of these amino acids exist in the $I$. album genome. Therefore, it is highly unlikely that $I$. album can synthesize these amino acids de novo. The serB gene for serine biosynthesis is also missing; however, other GSB also have an incomplete serine biosynthesis pathway but are autotrophic, which demonstrates that these organisms must have an alternative pathway for serine biosynthesis (Eisen et al., 2002). It would be premature to conclude that I. album cannot synthesize serine, and the related amino acids glycine and cysteine, from genome sequence data alone. However, it appears that several biosynthetic pathways for the synthesis of amino acids by I. album are incomplete. Consistent with all of these deductions, I. album cannot grow without yeast extract (Iino et al., 2010), which is rich in amino acids and oligopeptides. Finally, the I. album genome includes an oligopeptide transporter, a putative amino acid transporter, and several putative $\mathrm{Na}^{+}$/proline symporters.

\section{NITROGEN AND SULFUR METABOLISM}

The I. album genome does not encode any nif genes for nitrogenase or its assembly, which are highly conserved and universally present among GSB, nor does the genome encode any assimilatory enzymes that would enable it to use $\mathrm{NO}_{3}^{-}$or urea as potential nitrogen sources. As noted above, I. album does possess a periplasmicfacing NrfAH complex that can convert nitrite to ammonia during ammonification. However, the $\mathrm{NH}_{4}^{+}$transporter that is universally conserved among sequenced GSB is absent, and no other $\mathrm{NH}_{4}^{+}$ transporter of the common Amt/MEP/Rh family (Winkler, 2006) could be identified in the genome. Although it remains possible that the genome encodes an unrecognized ammonia transporter, it must presently be assumed that I. album depends on amino acids or peptides as its primary nitrogen source(s).

Assimilatory sulfate reduction genes are also not present. Considering that I. album may be dependent on certain exogenous amino acids, these compounds may satisfy a large portion of the cellular needs for nitrogen and sulfur. Alternatively, sulfide may be intracellularly assimilated via cysteine synthase. Sulfide transport is poorly understood, and thus it is unclear whether a sulfide transporter is present (or required) in I. album. If the ORFs IALB_1661-1663 actually encode a polysulfide reductase (see above), this enzyme could potentially allow sulfur assimilation by reduction of sulfur/polysulfides under anoxic conditions. Under oxic conditions, I. album appears to rely on reduced sulfur sources such as amino acids for sulfur assimilation. Another possible route of sulfur assimilation could be via nitrite reductase. In Wolinella succinogenes, the pentaheme nitrite reductase also exhibits sulfite reductase activity (Lukat et al., 2008). Future physiological and biochemical analyses will be required to determine the source(s) of sulfur for growth of I. album.

\section{FLAGELLA AND CHEMOTAXIS}

Chloroherpeton thalassium, which exhibits flexing and gliding motility (Gibson et al., 1984), is currently the only member of the phylum Chlorobi that has been shown to be motile. As isolated, observations by light microscopy suggested that I. album was not motile, and flagella were not observed by electron microscopy (Iino et al., 2010). However, the I. album genome contains a nearly 
complete set of genes for flagella in a 71-gene cluster (IALB_2496 to 2566; Figure 2) along with genes for chemotaxis and signal transduction. All known structural genes for the production of flagella, as well as all genes of the flagellar basal body secretion system, were identified. The only missing genes encode the chaperone proteins FlgN, FliT, and FliS, and the regulatory proteins FlhC and FlhD, which are not always essential for cell motility (Fraser et al., 1999; Minamino et al., 2000). Considering the (near) completeness of this gene cluster, I. album must have had flagella until very recently, and it is possible that the capacity to produce flagella was lost during efforts to grow this organism in the laboratory. Loss of flagella is very common among bacterial strains when they are grown under uniform conditions that have little or no selective pressure for retention of flagellar genes (Sellek et al., 2002).

Genes encoding the proteins CheA, CheB, CheR, CheW, CheY, CheZ, and a methyl-accepting chemotaxis protein (MCP), which are responsible for methylation-dependent chemotaxis, are also found in the 71-gene cluster for producing flagella. However, the specificity of the MCP for attractant(s) or repellent(s) is uncertain from sequence analysis, and this is the only MCP in the I. album genome. Although the chemotactic properties of I. album remain unclear, the presence of these genes suggests that I. album was chemotactic until very recently. Interestingly, even though they no longer have any genes for flagella, some of these chemotaxis genes still occur in the C. thalassium genome (cheBRW and $m c p$ ) and "Candidatus T. aerophilum" metagenome (cheW and mcp; Liu et al., 2012). These genes appear to be relics reflecting the loss of chemotaxis and possibly genes for flagellar biogenesis during evolution. If this interpretation is correct, it implies that these genes were present in the apparently motile ancestors of extant members of the phylum Chlorobi.

\section{GENE REGULATION}

Ignavibacterium album genome has 31 pairs of sensor histidine kinases and response regulators, some of which are fused into single proteins. Sixteen genes encoding sigma factors for RNA polymerase were also found. These numbers are significantly larger than the eight (pairs of) two-component system proteins and five genes for sigma factors found in a typical GSB, C. tepidum (Eisen et al., 2002), even when the numbers are normalized to reflect the difference in genome sizes (3.66 vs. $2.15 \mathrm{Mb}$ ). These observations strongly suggest that I. album has a much greater capacity than GSB to sense changes in its physicochemical environment, and regulate its gene expression accordingly in response. GSB often live under relatively constant conditions and have a uniform, strictly anaerobic, photolithoautotrophic lifestyle. These observations are also generally consistent with the predicted ability of I. album to perform swimming motility and chemotaxis, to respire under oxic and anoxic conditions, and to utilize various electron acceptors and donors.

\section{DISCUSSION}

Genome analysis for I. album has revealed a versatile, motile, nonphototrophic organism that is suggested to live under both oxic and anoxic conditions by using a variety of electron donors and acceptors. The metabolic capabilities of this organism are certainly more complex than was revealed in initial cultivation studies
(Iino et al., 2010), probably because of limitations imposed by the culture medium and the unknown and unsuspected nutritional deficiencies. I. album appears to be capable of mixotrophy by fixing $\mathrm{CO}_{2}$ using PFOR and KFOR and by performing at least certain steps of the reverse TCA cycle, possibly using $\mathrm{H}_{2}$ as electron donor. However, the organism would still be a heterotroph because of its apparent inability to synthesize several amino acids. Moreover, it is dependent upon exogenous amino acids not only for protein synthesis but also as sources of nitrogen (and possibly sulfur) as well (Figure 6). These inferences will have to be tested further by cultivation studies; in the case of $\mathrm{O}_{2}$ and motility, the initial observations have already been corrected by targeted cultivation studies and additional microscopic observations.

This metabolic and physiological description of I. album is strikingly different from that of GSB, and more generally for the members of the phylum Chlorobi prior to the discovery of I. album. However, this description shares a number of similarities with the predicted properties of "Candidatus T. aerophilum," including $\mathrm{O}_{2}$ preference/tolerance, the inability to synthesize certain amino acids, and the inability to oxidize sulfur or fix nitrogen (Liu et al., 2012). The genomic data suggest that these two organisms are probably examples of previously unsuspected diversity of physiological capabilities inherent among organisms belonging to the phylum Chlorobi. The previous perception of the apparently limited diversity for members of the Chlorobi was true because the organisms that had been grown axenically and studied only represented a small, relatively closely related group of organisms within the phylum, mostly obtained by applying a highly specific set of enrichment conditions (Overmann, 2006). It is likely that those culture conditions (anoxic conditions with high sulfide concentrations in the light) significantly favor the isolation of organisms (i.e., GSB) with very similar physiological capabilities. Such conditions were actually unfavorable for I. album, which apparently cannot oxidize sulfide completely to sulfate and probably produces more energy if at least some oxygen is present. Fortunately, in spite of the unfavorable growth conditions, I. album still grew and was isolated in axenic culture. However, other potential members of the Chlorobi probably have not survived unfavorable cultivation conditions in the past, which may have prevented their discovery, or they may not have been selected for further testing because the colonies were not pigmented. These observations indicate why culture-independent approaches, which have become more accessible due to advances in sequencing technology and reduction in costs, will continue to play an increasingly important role in revealing the metabolic and physiological diversity that exists among members of the phylum Chlorobi. In fact, "Candidatus T. aerophilum" was also identified and characterized in this way (Liu et al., 2012), and it is likely that additional interesting organisms will be identified and studied in this way in future studies.

Comparisons of the genome sequences of I. album and other members of the phylum Chlorobi, including the GSB, could have important implications for the evolutionary trajectory that extends from ancestral members to extant members of the phylum. Table 1 summarizes some of the differences in genome size and distribution of selected proteins among I. album, "Candidatus T. aerophilum," C. thalassium, and members of the family Chlorobiaceae. The latter include members of three well-characterized 
Table 1 | Summary of distribution of major properties for organisms belonging to the phylum Chlorobi.

\begin{tabular}{|c|c|c|c|c|}
\hline & I. album & "Ca. T. aerophilum"a & C. thalassium & Chlorobiaceae \\
\hline Genome size (Mb) & 3.66 & 3.18 & 3.29 & $1.97-3.13$ \\
\hline Photosynthetic apparatus & No & Yes & Yes & Yes \\
\hline Relationship with $\mathrm{O}_{2}$ & Oxic and anoxic & Oxic & Anoxic & Anoxic \\
\hline Reverse TCA cycle & Incomplete ${ }^{b}$ & Incomplete & Yes & Yes \\
\hline PFOR and $\mathrm{KFOR}^{\mathrm{C}}$ & Yes & Yes & Yes & Yes \\
\hline RNF complex & Yes & No & No & Some \\
\hline Type-1 NADH dehydrogenase & Two copies (14 and 11 SU) ${ }^{d}$ & Two copies (12 and $11 \mathrm{SU})^{\mathrm{d}}$ & Two copies (14 and $11 \mathrm{SU})^{\mathrm{d}}$ & One copy (11 SU) ${ }^{d}$ \\
\hline Complex III & $\mathrm{ACII} \mathrm{I}^{\mathrm{e}}$ & Both $\mathrm{ACII}{ }^{\mathrm{e}}$ and Cyt $b$-Rieske & Cyt $b$-Rieske & Cyt b-Rieske \\
\hline Terminal oxidases & Cyt $c a a_{3}, c b b_{3}, b d(1), b d(2)^{f}$ & Cyt $\mathrm{caa}_{3}$ & Cyt bd(2) & Cyt $c b b_{3}$ and/or $b d(1)$ \\
\hline Flagella genes & Yes & No & No & No \\
\hline Chemotaxis genes & Yes & Partial & Partial & No \\
\hline Sulfide oxidation to polysulfide & Yes & No & Yes & Yes \\
\hline Sulfur oxidation to sulfite & No & No & Nog & Most $^{g}$ \\
\hline Nitrogen fixation & No & No & Yes & Yes \\
\hline
\end{tabular}

${ }^{a}$ Inferences made from metagenome and metatranscriptome data (Liu et al., 2012). Additional genes could be present in the organism.

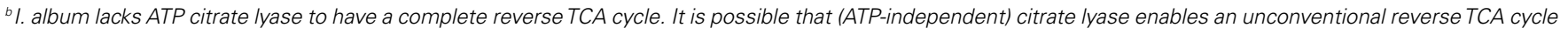
under certain growth conditions.

${ }^{c}$ PFOR, pyruvate:ferredoxin oxidoreductase; KFOR, 2-oxoglutarate:ferredoxin oxidoreductase

${ }^{d} S U$, subunits.

${ }^{e}$ ACIII, alternative complex III.

${ }^{\dagger}$ Two different cytochrome bd-quinol oxidases exist among Chlorobi. See Figures $\mathbf{6}$ and $\mathbf{8 B}$ for details.

${ }^{g}$ Most organisms belonging to the Chlorobiaceae have genes involved in oxidation of sulfide to sulfate, with a few exceptions (see Gregersen et al., 2011).

genera of GSB, and "Candidatus T. aerophilum" and C. thalassium represent family-level lineages of the class Chlorobea (Bryant et al., 2012; see Figure 1). These comparisons imply that many genes that contribute to the ability to acclimate to various environments, including electron transfer complexes and motility genes, were possibly lost during the evolutionary transition from ancestral members of the Chlorobi to the current GSB-type organisms, as they settled into relatively constant, sulfide-rich anoxic environments. This is consistent with a general trend toward genome size reduction. Some functions apparently were acquired to allow a better acclimation and eventually adaptation to specific environments. For example, the acquisition of $d s r$ genes (and a few other genes) in some GSB allowed complete oxidation of sulfur to sulfite (and ultimately to sulfate), which provides better energy conservation and more electrons for $\mathrm{CO}_{2}$ fixation per sulfide consumed than the incomplete oxidation to elemental sulfur allowed by sqr genes alone. Thus, possession of $d s r$ genes is highly advantageous to GSB under sulfide-limiting conditions (Holkenbrink et al., 2011). It is also important to remember that

\section{REFERENCES}

Antonov, I., and Borodovsky, M. (2010). Genetack: frameshift identification in protein-coding sequences by the Viterbi algorithm. J. Bioinform. Comput. Biol. 8, 535-551.

Aoshima, M., Ishii, M., and Igarashi, Y. (2004a). A novel enzyme, citryl-CoA synthetase, catalysing the first step of the citrate cleavage reaction in
Hydrogenobacter thermophilus TK-6. Mol. Microbiol. 52, 751-761.

Aoshima, M., Ishii, M., and Igarashi, Y. (2004b). A novel enzyme, cirtylCoA lyase, catalysing the second step of the citrate cleavage reaction in Hydrogenobacter thermophilusTK-6. Mol. Microbiol. 52, 763-770.

Battchikova, N., Eisenhut, M., and Aro, E. M. (2011). Cyanobacterial

the available genomes represent only a very small sampling of the organismal history that represents a long and complex evolutionary process experienced by the members of the phylum Chlorobi. As more and more organisms will be discovered in the future, the hypotheses proposed here will be confirmed, challenged, and modified, and will lead to a description of this phylum that is likely to be far more diverse than imaginable just a few years ago.

\section{ACKNOWLEDGMENTS}

The authors thank the Penn State Genomics Core Facility in the Huck Institutes for the Life Sciences for their assistance in genome sequencing. The authors thank Dr. Eric Boyd (Montana State University) for providing functional insights concerning the hydrogenases of I. album. The authors acknowledge the Division of Chemical Sciences, Geosciences, and Biosciences, Office of Basic Energy Sciences of the U.S. Department of Energy through Grant DE-FG02-94ER20137 for supporting biochemical and genomic studies on green bacteria.

NDH-1 complexes: novel insights and remaining puzzles. Biochim. Biophys. Acta 1807, 935-944.

Biegel, E., Schmidt, S., González, J. M., and Müller, V. (2011). Biochemistry, evolution and physiological function of the Rnf complex, a novel ion-motive electron transport complex in prokaryotes. Cell. Mol. Life Sci. 68, 613-634.
Bott, M., and Dimroth, P. (1994). Klebsiella pneumoniae genes for citrate lyase and citrate lyase ligase: localization, sequencing, and expression. Mol. Microbiol. 14, 347-356.

Bryant, D. A., and Frigaard, N.-U. (2006). Prokaryotic photosynthesis and phototrophy illuminated. Trends Microbiol. 14, 488-496. 
Bryant, D. A., Liu, Z., Li, T., Zhao, F., Garcia Costas, A. M., Klatt, C. G., Ward, D. M., Frigaard, N. U., and Overmann, J. (2012) “Comparative and functional genomics of anoxygenic green bacteria from the taxa Chlorobi, Chloroflexi, and Acidobacteria," in Advances in Photosynthesis and Respiration, Vol. 35, Functional Genomics and Evolution of Photosynthetic Systems, eds R. L. Burnap, and W. Vermaas (Dordrecht: Springer), 47-102.

Buchanan, B. B., and Arnon, D. I. (1990). A reverse KREBS cycle in photosynthesis: consensus at last. Photosyn. Res. 24, 47-53.

Ciccarelli, F. D., Doerks, T., von Mering, C., Creevey, C. J., Snel, B., and Bork, P. (2006). Toward automatic reconstruction of a highly resolved tree of life. Science 311, 12831287.

Dailey, H. A., and Dailey, T. A. (1996). Protoporphyrinogen oxidase of Myxococcus xanthus. Expression, purification, and characterization of the cloned enzyme. J. Biol. Chem. 271, 8714-8718.

D'Mello, R., Hill, S., and Poole, R. K. (1996). The cytochrome bd quinol oxidase in Escherichia coli has an extremely high oxygen affinity and two oxygen-binding haems: implications for regulation of activity in vivo by oxygen inhibition. Microbiology 142, 755-763.

Dobbek, H., Gremer, L., Meyer, O., and Huber, R. (1999). Crystal structure and mechanism of $\mathrm{CO}$ dehydrogenase, a molybdo ironsulfur flavoprotein containing Sselanylcysteine. Proc. Natl. Acad. Sci. U.S.A. 96, 8884-8889.

Eisen, J. A., Nelson, K. E., Paulsen, I. T., Heidelberg, J. F., Wu, M., Dodson, R. J., Deboy, R., Gwinn, M. L., Nelson, W. C., Haft, D. H., Hickey, E. K., Peterson, J. D., Durkin, A. S., Kolonay, J. L., Yang, F., Holt, I., Umayam, L. A., Mason, T., Brenner, M., Shea, T. P., Parksey, D., Nierman, W. C., Feldblyum, T. V., Hansen, C. L., Craven, M. B., Radune, D., Vamathevan, J., Khouri, H., White, O., Gruber, T. M., Ketchum, K. A., Venter, J. C., Tettelin, H., Bryant, D. A., and Fraser, C. M. (2002). The complete genome sequence of Chlorobium tepidum TLS, a photosynthetic, anaerobic, green-sulfur bacterium. Proc. Natl. Acad. Sci. U.S.A. 99, 9509-9514.

Ewing, B., Hillier, L., Wendl, M., and Green, P. (1998). Basecalling of automated sequencer traces using phred. I. Accuracy assessment. Genome Res. 8, 175-185.
Feng, X., Tang, K. H., Blankenship, R. E., and Tang, Y. J. (2010). Metabolic flux analysis of the mixotrophic metabolisms in the green sulfur bacterium Chlorobaculum tepidum. J. Biol. Chem. 285, 39544-39550.

Forte, E., Urbani, A., Saraste, M., Sarti, P., Brunori, M., and Giuffrè, A. (2001). The cytochrome cbb3 from Pseudomonas stutzeridisplays nitric oxide reductase activity. Eur. J. Biochem. 268, 6486-6491.

Fraser, G. M., Bennett, J. C., and Hughes, C. (1999). Substrate-specific binding of hook-associated proteins by FlgN and FliT, putative chaperones for flagellum assembly. Mol. Microbiol. 32, 569-580.

Frigaard, N.-U., and Bryant, D. A. (2004). Seeing green bacteria in a new light: genomics-enabled studies of the photosynthetic apparatus in green sulfur bacteria and filamentous anoxygenic phototrophic bacteria. Arch. Microbiol. 182, 265-276.

Frigaard, N.-U., Maresca, J. A., Yunker, C. E., Jones, A. D., and Bryant, D. A. (2004). Genetic manipulation of carotenoid biosynthesis in the green sulfur bacterium Chlorobium tepidum. J. Bacteriol. 186, 5210-5220.

Frigaard, N.-U., and Dahl, C. (2009). Sulfur metabolism in phototrophic sulfur bacteria. Adv. Microb. Physiol. 54, 103-200.

Gao, X., Xin, Y., and Blankenship, R. E. (2009). Enzymatic activity of the alternative complex III as a menaquinol:auracyanin oxidoreductase in the electron transfer chain of Chloroflexus aurantiacus. FEBS Lett. 583, 3275-3279.

Garcia Costas, A. M., Liu, Z., Tomsho, L. P., Schuster, S. C., Ward, D. M., and Bryant, D. A. (2012a). Complete genome of Candidatus Chloracidobacterium thermophilum, a chlorophyll-based photoheterotroph belonging to the phylum Acidobacteria. Environ. Microbiol. 14, 177-190.

Garcia Costas, A. M., Tsukatani, Y., Rijpstra, M., Schouten, S., Welander, P. V., Summons, R. E., and Bryant, D. A. (2012b). Identification of the bacteriochlorophylls, carotenoids, quinones, lipids, and hapanoids of "Candidatus Chloracidobacterium thermophilum." J. Bacteriol. 194, 1158-1168.

Garica-Horsman, J. A., Barquera, B., Rumbley, J., Ma, J., and Gennis, R. B. (1994). The superfamily of hemecopper respiratory oxidases. J. Bacteriol. 176, 5587-5600.

Gibson, J., Pfennig, N., and Waterbury, J. B. (1984). Chloroherpeton thalassium gen. nov.et spec. nov.a non-filamentous, flexing and gliding green sulfur bacterium. Arch. Microbiol. 138, 96-101.

Giuffrè, A., Stubauer, G., Sarti, P., Brunori, M., Zumft, W. G., Buse, G., and Soulimane, T. (1999). The heme-copper oxidases of Thermus thermophilus catalyze the reduction of nitric oxide: evolutionary implications. Proc. Natl. Acad. Sci. U.S.A. 96, 14718-14723.

Gordon, D., Abajian, C., and Green, P. (1998). Consed: a graphical tool for sequence finishing. Genome Res. 8, 195-202.

Gregersen, L. H., Bryant, D. A., and Frigaard, N. U. (2011). Mechanisms and evolution of oxidative sulfur metabolism in green sulfur bacteria. Front. Microbiol. 2:116. doi:10.3389/fmicb.2011.00116

Hassani, B. K., Steunou, A. S., Liotenberg, S., Reiss-Husson, F., Astier, C., and Ouchane, S. (2010). Adaptation to oxygen: role of terminal oxidases in photosynthesis initiation in the purple photosynthetic bacterium, Rubrivivax gelatinosus. J. Biol. Chem. 285, 19891-19899.

Heising, S., Richter, L., Ludwig, W., and Schink, B. (1999). Chlorobium ferrooxidans sp. nov., a phototrophic green sulfur bacterium that oxidizes ferrous iron in coculture with a "Geospirillum" sp. strain. Arch. Microbiol. 172, 116-124.

Hensel, M., Hinsley, A. P., Nikolaus, T., Sawers, G., and Berks, B. C. (1999). The genetic basis of tetrathionate respiration in Salmonella typhimurium. Mol. Microbiol. 32, 275-287.

Hinsley, A. P., and Berks, B. C. (2002). Specificity of respiratory pathways involved in the reduction of sulfur compounds by Salmonella enterica. Microbiology 148, 3631-3638.

Holkenbrink, C., OcónBarbas, S. Mellerup, A., Otaki, H., and Frigaard, N.-U. (2011). Sulfur globule oxidation in green sulfur bacteria is dependent on the dissimilatory sulfite reductase system. Microbiology 157, 1229-1239.

Hügler, M., and Sievert, S. M. (2011). Beyond the Calvin cycle: autotrophic carbon fixation in the ocean. Ann. Rev. Mar. Sci. 3, 261-289.

Iino, T., Mori, K., Uchino, Y., Nakagawa, T., Harayama, S., and Suzuki, K. (2010). Ignavibacterium album gen. nov., sp. nov., a moderately thermophilic anaerobic bacterium isolated from microbial mats at a terrestrial hot spring and proposal of Ignavibacteria classis nov., for a novel lineage at the periphery of green sulfur bacteria. Int. J. Syst. Evol. Microbiol. 60, 1376-1382.

Jagannathan, B., and Golbeck, J. H. (2008). Unifying principles in homodimeric type I photosynthetic reaction centers: properties of $\mathrm{PscB}$ and the FA, FB, and FXironsulfur clusters in green sulfur bacteria. Biochim. Biophys. Acta 1777, 1535-1544.

King, G. M., and Weber, C. F. (2007). Distribution, diversity and ecology of aerobic CO-oxidizing bacteria. Nat. Rev. Microbiol. 5, 107-118.

Lagesen, K., Hallin, P., Rødland, E. A., Stærfeldt, H. H., Rognes, T., and Ussery, D. W. (2007). RNAmmer: consistent and rapid annotation of ribosomal RNA genes. Nucleic Acids Res. 35, 3100-3108.

Li, H., Jubelirer, S., Garcia Costas, A. M., Frigaard, N.-U., and Bryant, D. A. (2009). Multiple antioxidant proteins protect Chlorobaculum tepidum against oxygen and reactive oxygen species. Arch. Microbiol. 191, 853-867.

Liu, Z., Klatt, C. G., Ludwig, M., Rusch, D. B., Jensen, S. I., Kühl, M., Ward, D. M., and Bryant, D. A. (2012). "Candidatus Thermochlorobacter aerophilum": an aerobic chlorophotoheterotrophic member of the phylum Chlorobi defined by metagenomics and metratranscriptomics. ISME J. doi:10.1038/ismej.2012.24

Ludwig, W., and Klenk, H. P. (2001) "Overview: a phylogenetic backbone and taxonomic framework for prokaryotic systematics," in Bergey's Manual of Systematic Bacteriology, Vol. 1, 2nd Edn, eds D. R. Boone and R. W. Castenholz (Berlin: Springer), 49-65.

Lukat, P., Rudolf, M., Stach, P., Messerschmidt, A., Kroneck, P. M., Simon, J., and Einsle, O. (2008). Binding, and reduction of sulfite by cytochrome $\mathrm{c}$ nitrite reductase. Biochemistry 47, 2080-2086.

Maresca, J. A., Romberger, S. P., and Bryant, D. A. (2008). Isorenieratene biosynthesis in green sulfur bacteria requires the cooperative actions of two carotenoid cyclases. J. Bacteriol. 190, 6384-6391.

McGlynn, S. E., Shepard, E. M., Winslow, M. A., Naumov, A. V., Duschene, K. S., Posewitz, M. C., Broderick, W. E., Broderick, J. B., and Peters, J. W. (2008). HydF as a scaffold protein in [FeFe] hydrogenase $\mathrm{H}$-cluster biosynthesis. FEBS Lett. 582, 2183-2187.

Meyer, M., Dimroth, P., and Bott, M. (2001). Catabolite repression of the citrate fermentation genes 
in Klebsiella pneumoniae: evidence for involvement of the cyclic AMP receptor protein. J. Bacteriol. 183, 5248-5256

Minamino, T., Chu, R., Yamaguchi, S., and Macnab, R. M. (2000). Role of FliJ in flagellar protein export in Salmonella. J. Bacteriol. 182, 4207-4215.

Mulder, D. W., Shepard, E. M., Meuser, J. E., Joshi, N., Posewitz, M. C., Broderick, J. B., and Peters, J. W. (2011). Insights into $[\mathrm{FeFe}]$-hydrogenase structure, mechanism, and maturation. Structure 19, 1038-1052.

Overmann, J. (2006) "The family Chlorobiaceae," in The Prokaryotes, Vol. 7, eds M. Dworkin, S. Falkow, E. Rosenberg, K. H. Schleifer, and E. Stackebrandt (Dordrecht: Springer), 359-378.

Overmann, J. (2008) "Ecology of phototrophic sulfur bacteria," in Sulfur Metabolism in Phototrophic Organisms, eds R. Hell, C. Dahl, D. B. Knaff, and T. Leustek (Dordrecht: Springer), 375-396.

Pereira, M. M., Refojo, P. N., Hreggvidsson, G. O., Hjorleifsdottir, S., and Teixeira, M. (2007). The alternative complex III from Rhodothermus marinus - a prototype of a new family of quinol:electron acceptor oxidoreductases. FEBS Lett. 581, 4831-4835.

Posewitz, M. C., Mulder, D. W., and Peters, J. W. (2008). New frontiers in hydrogenase structure and biosynthesis. Curr. Chem. Biol. 2, 178-199.

Preisig, O., Zufferey, R., Thöny-Meyer, L., Appleby, C. A., and Hennecke, H. (1996). A high-affinity cbb3-type cytochrome oxidase terminates the symbiosis-specific respiratory chain of Bradyrhizobium japonicum. J. Bacteriol. 178, 1532-1538.

Refojo, P. N., Teixeira, M., and Pereira, M. M. (2010a). The alternative complex III: a different architecture using known building modules. Biochim. Biophys. Acta 1797, 1869-1876.
Refojo, P. N., Teixeira, M., and Pereira, M. M. (2010b). The alternative complex III of Rhodothermus marinus and its structural and functional association with caa3 oxygen reductase. Biochim. Biophys. Acta 1797, 1477-1482.

Schut, G. J., and Adams, M. W. (2009). The iron-hydrogenase of Thermotoga maritima utilizes ferredoxin and $\mathrm{NADH}$ synergistically: a new perspective on anaerobic hydrogen production. J. Bacteriol. 191, 4451-4457.

Sellek, R. E., Escudero, R., Gil, H., Rodríguez, I., Chaparro, E., PérezPastrana, E., Vivo, A., and Anda, P. (2002). In vitro culture of Borreliagarinii results in loss of flagella and decreased invasiveness. Infect. Immun. 70, 4851-4858.

Simon, J. (2002). Enzymology and bioenergetics of respiratory nitrite ammonification. FEMS Microbiol. Rev. 26, 285-309.

Soboh, B., Linder, D., and Hedderich, R. (2004). A multisubunit membranebound $[\mathrm{NiFe}$ hydrogenase and an NADH-dependent Fe-only hydrogenase in the fermenting bacterium Thermoanaerobacter tengcongensis. Microbiology 150, 2451-2463.

Tang, K. H., Tang, Y. J., and Blankenship, R. E. (2011). Carbon metabolic pathways in phototrophic bacteria and their broader evolutionary implications. Front. Microbiol. 2:165. doi:10.3389/fmicb.2011.00165

Tersteegen, A., Linder, D., Thauer, R. K., and Hedderich, R. (1997). Structures and functions of four anabolic 2-oxoacid oxidoreductase in Methanobacterium thermoautotrophicum. Eur. J. Biochem. 244, 862-868.

Tsukatani, Y., Romberger, S. P., Golbeck, J. H., and Bryant, D. A. (2012). Characterization of the oxygen-tolerant, homodimeric type-1 reaction centers of
"Candidatus Chloracidobacterium thermophilum." J. Biol. Chem. 287, 5720-5732.

Upadhyay, A. K., Hooper, A. B. and Hendrich, M. P. (2006). NO reductase activity of the tetraheme cytochrome c554 of Nitrosomonas europaea. J. Am. Chem. Soc. 128 4330-4337.

van der Oost, J., de Boer, A. P., de Gier, J. W., Zumft, W. G., Stouthamer, A. H., and van Spanning, R. J. (1994). The heme-copper oxidase family consists of three different types of terminal oxidases and is related to nitric oxide reductase. FEMS Microbiol. Lett. 121, $1-9$.

Verhagen, M. F., O'Rourke, T., and Adams, M. W. (1999). The hyperthermophilic bacterium, Thermotoga maritima, contains an unusually complex iron-hydrogenase: amino acid sequence analyses versus biochemical characterization. Biochim. Biophys. Acta 1412, 212-229.

Vignais, P. M., and Billoud, B. (2007). Occurrence, classification, and biological function of hydrogenases: an overview. Chem. Rev. 107, 4206-4272.

Wahlund, T. M., and Madigan, M. T. (1993). Nitrogen fixation by the thermophilic green sulfur bacterium Chlorobium tepidum. J. Bacteriol. 175, 474-478.

Wahlund, T. M., and Tabita, F. R (1997). The reductive tricarboxylic acid cycle of carbon dioxide assimilation: initial studies and purification of ATP-citrate lyase from the green sulfur bacterium Chlorobium tepidum. J. Bacteriol. 179, 4859-4867.

Winkler, F. K. (2006). Amt/MEP/Rh proteins conduct ammonia. Pflugers Arch. 451, 701-707.

Wu, D., Raymond, J., Wu, M., Chatterji, S., Ren, Q., Graham, J. E., Bryant, D. A., Robb, F., Colman, A., Tallon, L. J., Badger, J. H., Madupu, R.,
Ward, N. L., and Eisen, J. A. (2009). Complete genome sequence of the aerobic CO-oxidizing thermophile Thermomicrobium roseum. PLoS ONE 4, e4207. doi:10.1371/journal.pone.0004207

Yanyushin, M. F., del Rosario, M. C., Brune, D. C., and Blankenship, R. E. (2005). New class of bacterial membrane oxidoreductases. Biochemistry 44, 10037-10045.

Zumft, W. G., and Körner, H. (2007). "Nitrous oxide reductases," in Biol ogy of the Nitrogen Cycle, eds $\mathrm{H}$. Booth, S. J. Ferguson, and W. E. Newton (Dordrecht: Springer), 67-81.

Conflict of Interest Statement: The authors declare that the research was conducted in the absence of any commercial or financial relationships that could be construed as a potential conflict of interest.

Received: 17 March 2012; paper pending published: 12 April 2012; accepted: 04 May 2012; published online: 29 May 2012.

Citation: Liu Z, Frigaard $N-U$, Vogl $K$, Iino $T$, Ohkuma $M$, Overmann $J$ and Bryant DA (2012) Complete genome of Ignavibacterium album, a metabolically versatile, flagellated, facultative anaerobe from the phylum Chlorobi. Front. Microbio. 3:185. doi: 10.3389/fmicb.2012.00185

This article was submitted to Frontiers in Evolutionary and Genomic Microbiology, a specialty of Frontiers in Microbiology. Copyright (c) 2012 Liu, Frigaard, Vogl, Iino, Ohkuma, Overmann and Bryant. This is an open-access article distributed under the terms of the Creative Commons Attribution Non Commercial License, which permits non-commercial use, distribution, and reproduction in other forums, provided the original authors and source are credited. 